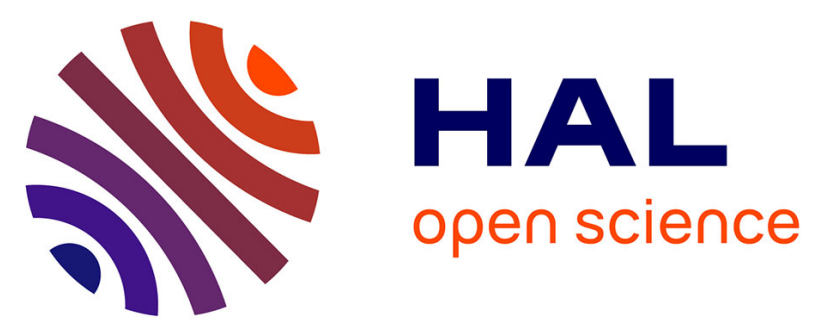

\title{
A Simulation Model for the Evaluation of the Electrical Power Potential Harnessed by a Marine Current Turbine
}

Seifeddine Benelghali, Rémi Balme, Karine Le Saux, Mohamed Benbouzid, Jean Frédéric Charpentier, Frédéric Hauville

\section{- To cite this version:}

Seifeddine Benelghali, Rémi Balme, Karine Le Saux, Mohamed Benbouzid, Jean Frédéric Charpentier, et al.. A Simulation Model for the Evaluation of the Electrical Power Potential Harnessed by a Marine Current Turbine. IEEE Journal of Oceanic Engineering, 2007, 32 (4), pp.786-797. 10.1109/JOE.2007.906381 . hal-00524613

\section{HAL Id: hal-00524613 \\ https://hal.science/hal-00524613}

Submitted on 8 Oct 2010

HAL is a multi-disciplinary open access archive for the deposit and dissemination of scientific research documents, whether they are published or not. The documents may come from teaching and research institutions in France or abroad, or from public or private research centers.
L'archive ouverte pluridisciplinaire HAL, est destinée au dépôt et à la diffusion de documents scientifiques de niveau recherche, publiés ou non, émanant des établissements d'enseignement et de recherche français ou étrangers, des laboratoires publics ou privés. 


\title{
Peer-Reviewed Technical Communication
}

\section{A Simulation Model for the Evaluation of the Electrical Power Potential Harnessed by a Marine Current Turbine}

\author{
Seif Eddine Ben Elghali, Student Member, IEEE, Rémi Balme, Karine Le Saux, \\ Mohamed El Hachemi Benbouzid, Senior Member, IEEE, Jean Frédéric Charpentier, Member, IEEE, and
}

Frédéric Hauville

\begin{abstract}
This paper deals with the development of a Matlab-Simulink model of a marine current turbine system through the modeling of the resource and the rotor. The simulation model has two purposes: performances and dynamic loads evaluation in different operating conditions and control system development for turbine operation based on pitch and speed control. In this case, it is necessary to find a compromise between the simulation model accuracy and the control-loop computational speed. The blade element momentum (BEM) approach is then used for the turbine modeling. As the developed simulation model is intended to be used as a sizing and site evaluation tool for current turbine installations, it has been applied to evaluate the extractable power from the Raz de Sein (Brittany, France). Indeed, tidal current data from the Raz de Sein are used to run the simulation model over various flow regimes and yield the power capture with time.
\end{abstract}

Index Terms-Marine technology, Matlab-Simulink, model, resource, rotor, simulation, tidal current.

\section{INTRODUCTION}

O CEANS, covering more than $70 \%$ of the earth, have long been acknowledged as a vast renewable energy source. The energy is stored in oceans partly as thermal energy, partly as kinetic energy (waves and currents), and also in chemical and biological products. Numerous techniques for extracting

Manuscript received April 6, 2007; revised July 5, 2007; accepted July 31, 2007. This work was supported by the Brest Métropole Océane (BMO) and the European Social Fund (ESF). It was done within the framework of the Marine Renewable Energy Commission of the Brittany Maritime Cluster (Pôle Mer Bretagne).

Associate Editor: H. Maeda.

S. E. Ben Elghali and M. E. H. Benbouzid are with the Laboratoire d'Ingénierie Mécanique et Electrique (LIME), University of Western Brittany, 29238 Brest Cedex 3, France (e-mail: benelghali@univ-brest.fr; m.benbouzid@ieee.org).

R. Balme and K. Le Saux were with the Laboratoire d'Ingénierie Mécanique et Electrique (LIME), University of Western Brittany, 29238 Brest Cedex 3, France. They are now with the French Naval Academy, Lanveoc-Poulmic, 29240 Brest Armées, France (e-mail: balme@eleves.ecole-navale.fr; lesaux@eleves.ecole-navale.fr).

J. F. Charpentier and F. Hauville are with the French Naval Academy Research Institute (IRENav), French Naval Academy, Lanveoc-Poulmic, 29240 Brest Armées, France (e-mail: charpentier@ecole-navale.fr; hauville@ecolenavale.fr).

Color versions of one or more of the figures in this paper are available online at http://ieeexplore.ieee.org.

Digital Object Identifier 10.1109/JOE.2007.906381 energy from the sea have been suggested, most of which can be included in one of the following categories: wave energy, marine and tidal current energy, ocean thermal energy, energy from salinity gradients (osmosis), and cultivation of the marine biomass. The kinetic energy present in marine and tidal currents can be converted into electricity using relatively conventional turbine technology. Harnessing the kinetic energy in waves presents a different set of technical challenges and a wide variety of designs have been suggested. Ocean thermal energy conversion is possible in locations with large temperature differences, extracting energy with a heat engine. Salinity gradients can be exploited for energy extraction through the osmotic process. The cultivation of the marine biomass can yield many useful products, including renewable fuels for electricity generation. However, due to technology limitations and economic considerations, osmotic and thermal energy developments are limited [1]-[3].

Only a fraction of the global ocean energy resource is to be found in sites which are economically feasible to explore with available technology. However, this fraction could still make a considerable contribution to electricity supply. This is the reason why the marine renewable sector is currently the focus of much industrial and academic research around the world [4], [5]. Sites with attractive wave climate and intense tidal currents are abundant near the European coastline. It has been shown that $48 \%$ of the European tidal resource is in the United Kingdom, $42 \%$ in France, and 8\% in Ireland [6]. There are basically the following two ways of generating electricity from marine and tidal currents: by building a tidal barrage across an estuary or a bay in high-tide areas, or by extracting energy from free-flowing water (tidal kinetic energy). Within the last few decades, developers have shifted towards technologies that capture tidally driven coastal currents or tidal stream. Indeed, very large amounts of energy are available in coastal waters [1], [7]-[13]. There are many areas of the world in which extreme tidal currents are observed. Three examples in France are shown in Fig. 1. The Raz Blanchard situated in Cap de la Hague experiences extreme tidal currents exceeding $8 \mathrm{kn}$ and leading to a large amount of kinetic energy flux.

It is, then, obvious that there is a need to quantify the potential for generating electricity from these various sites [14]. This paper reports then on the development of a practical Matlab-Simulink simulation tool based on the modeling of 


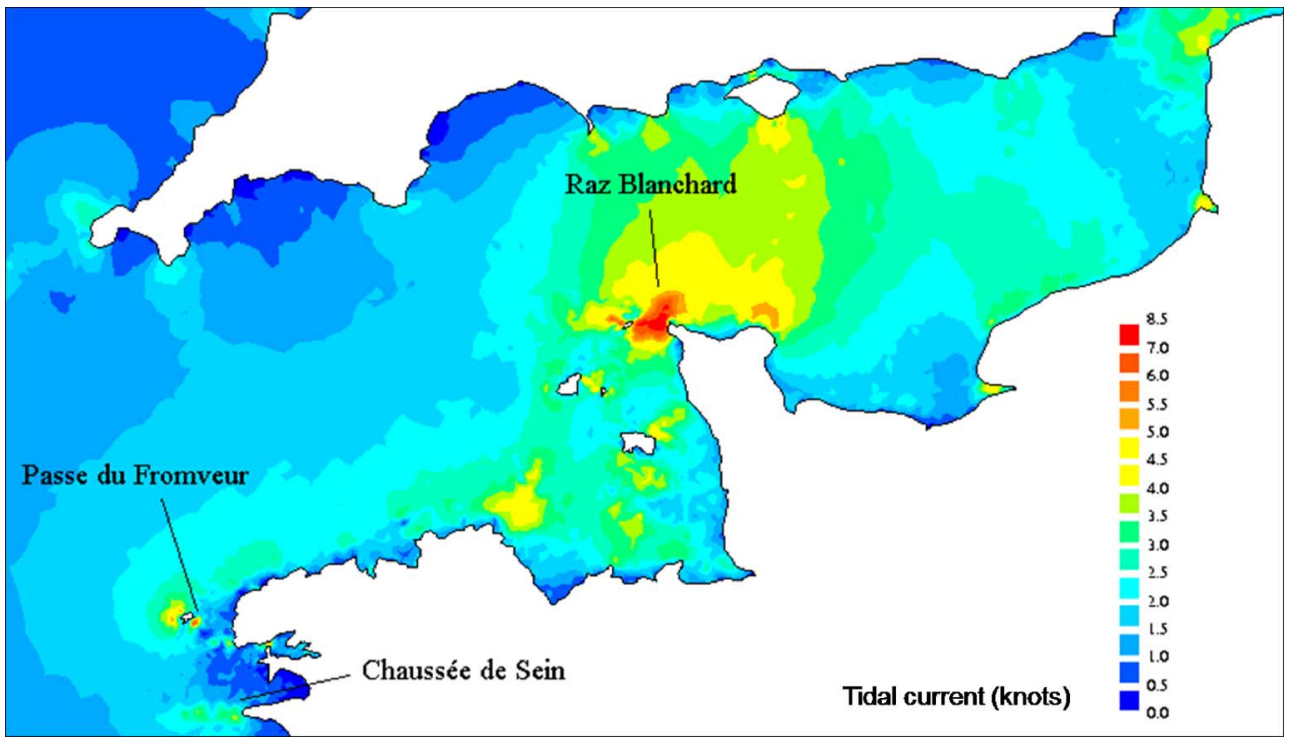

Fig. 1. Raz Blanchard, Fromveur, and Raz de Sein sites in the French western coast.

the resource and the tidal turbine rotor. The blade element momentum (BEM) approach is in this case used for the turbine modeling.

Matlab-Simulink, a general-purpose software package for dynamic systems, has been selected to carry out the modeling task for many reasons. Indeed, Simulink is a platform for multidomain simulation and model-based design for dynamic systems. It provides an interactive graphical environment and a customizable set of block libraries, and can be extended for specialized applications. This makes it the best candidate for accomplishing the objective of fostering interdisciplinary integration (hydrodynamics and electromechanics). Simulink being integrated with Matlab provides immediate access to an extensive range of tools for algorithm development, data visualization, data analysis and access, and numerical computation. Moreover, Matlab-Simulink allows automatically generating code for direct implementation and experimental tests.

The proposed simulation tool has been applied to assess the extractable power from the Raz de Sein (Brittany, France) as it is a well-characterized site in terms of tidal current.

\section{Resource Modeling}

The attractions of tidal currents for renewable energy developers are obvious. The medium, seawater, is more than 800 times denser than air and the astronomic nature of the underlying driving mechanism results in an essentially predictable resource, although subject to weather-related fluctuations.

As a renewable resource, tidal current flow is very predictable, to within $98 \%$ accuracy for decades. Tidal current charts are accurate to within minutes, for years ahead. The weather variations (wind, swells) lead to second-order variations in the resources. Tidal current is mainly independent of prevailing weather conditions such as wind, fog, rain, and clouds that can impact other renewable generation forecasts. Solar generation is altered by rain, clouds, and fog. Wind turbines are influenced by calm weather, yet tidal cycles are as reliable as the rising of the moon. While solar and wind are valuable renewable resources, neither can be plotted with the predictability of tidal energy. Thus, reliable amounts of tidal power can be forecast with confidence. This predictability is critical for successful integration of renewable resources into the electrical grid [7].

\section{A. Tidal Resource}

The global marine current energy resource is mostly driven by tides and to a lesser extent by thermal and density effects. The tides cause water to flow inwards twice each day (flood tide) and seawards twice each day (ebb tide) with a period of approximately $12 \mathrm{~h}$ and $24 \mathrm{~min}$ (a semidiurnal tide), or once both inwards and seawards in approximately $24 \mathrm{~h}$ and $48 \mathrm{~min}$ (a diurnal tide). In most locations, the tides are a combination of the semidiurnal and diurnal effects, with the tide being named after the most dominant type. The strength of the currents varies, depending on the proximity of the moon and sun relative to earth. The magnitude of the tide-generating force is about $68 \%$ moon and $32 \%$ sun due to their respective masses and distance from earth. Where the semidiurnal tide is dominant, the largest marine currents occur at new moon and full moon (spring tides) and the lowest at the first and third quarters of the moon (neap tides). With diurnal tides, the current strength varies with the declination of the moon (position of the moon relative to the equator). The largest currents occur at the extreme declination of the moon and lowest currents at zero declination. Further differences occur due to changes between the distances of the moon and sun from earth, their relative positions with reference to earth, and varying angles of declination. These occur with a periodicity of two weeks, one month, one year or longer, and are entirely predictable [6], [15].

The resource assessment is generally based on oceanographic databases containing data with a fixed grid square resolution. The main key criteria are as follows: maximum spring current velocity, maximum neap current velocity, seabed depth, maximum probable waveheight in 50 years, seabed slope, significant 


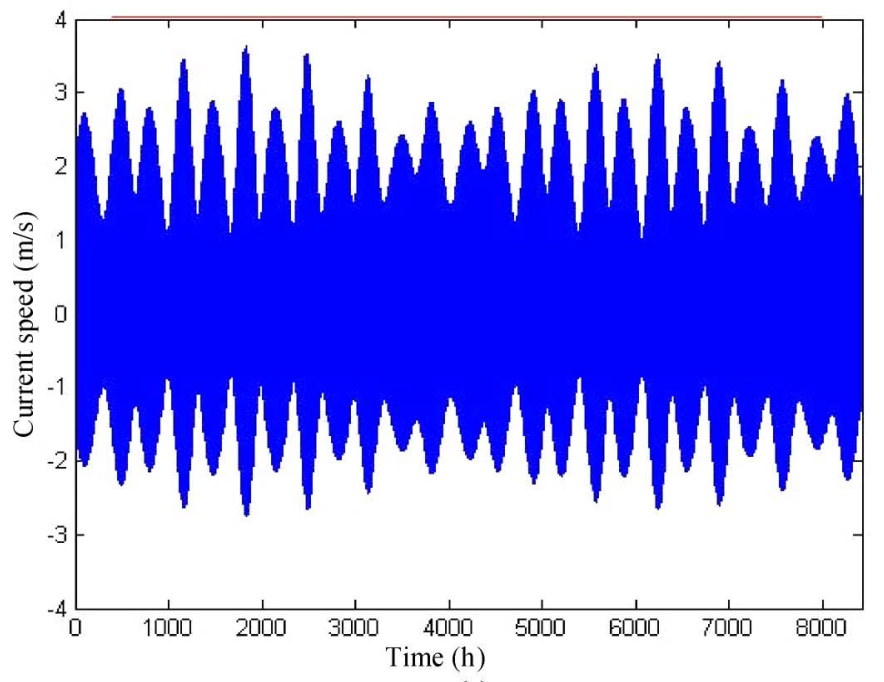

(a)

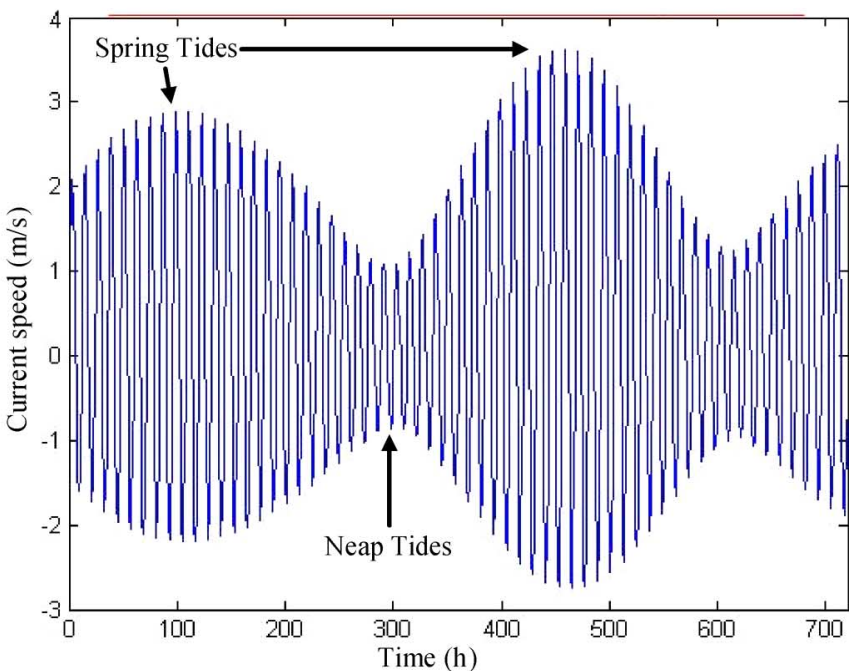

(b)

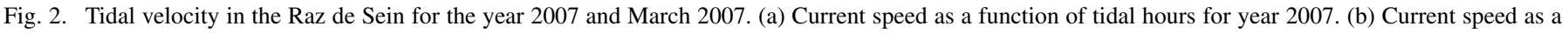
function of tidal hours for march 2007.

waveheight, and the distance from land [10], [16], [17]. For illustration, Fig. 2 shows the theoretical tidal velocity in the Raz de Sein for the year 2007 and March 2007.

\section{B. Resource Potential}

The total kinetic power in a marine current turbine has a similar dependence to that of a wind turbine and is governed by the following equation [6], [18], [19]:

$$
P=\frac{1}{2} \rho A V_{\text {tide }}^{3}
$$

where $\rho$ is the fluid density, $A$ is the cross-sectional area of the turbine, and $V_{\text {tide }}$ is the fluid velocity. However, a marine energy converter or turbine can only harness a fraction of this power due to losses and (1) is modified as follows:

$$
P=\frac{1}{2} \rho C_{p} A V_{\text {tide }}^{3}
$$

$C_{p}$ is known as the power coefficient and is essentially the percentage of mechanical power that can be extracted from the fluid stream by the turbine and takes into account its efficiency. This coefficient is limited to $16 / 27$ by the well-known Betz law. For wind generators, $C_{p}$ has typical values in the range 0.25-0.3. The upper limit is for highly efficient machines with low mechanical losses. For marine turbines, $C_{p}$ is estimated to be in the range $0.35-0.5[20]$.

\section{Resource Modeling}

1) Installation Site: The Raz de Sein site was chosen above several others listed in the European Commission report EUR16683 [21] due to the presence of high-velocity current coupled with appropriate depths suitable for marine turbine. Moreover, the marine current velocity distribution for most of the time is greater than the minimum, estimated to be $1 \mathrm{~m} / \mathrm{s}$, required for economic deployment of marine turbines [21], [22]. The studied area is shown by Fig. 3(a), where A and C are the area ends and $\mathrm{B}$ the expected installation site for the

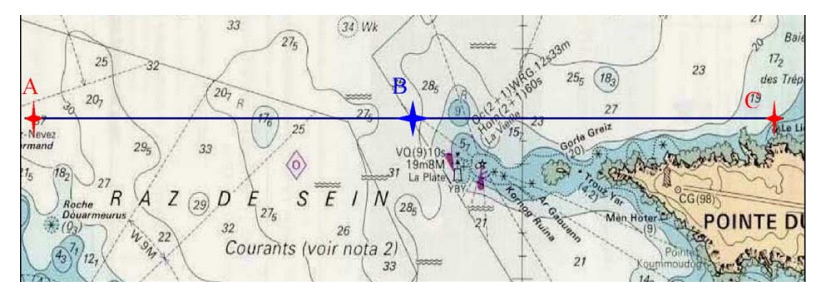

(a)

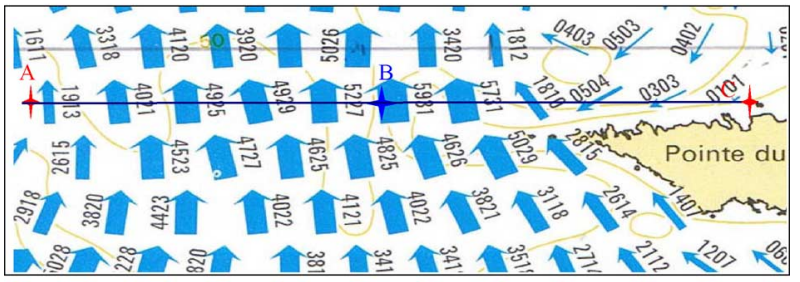

(b)

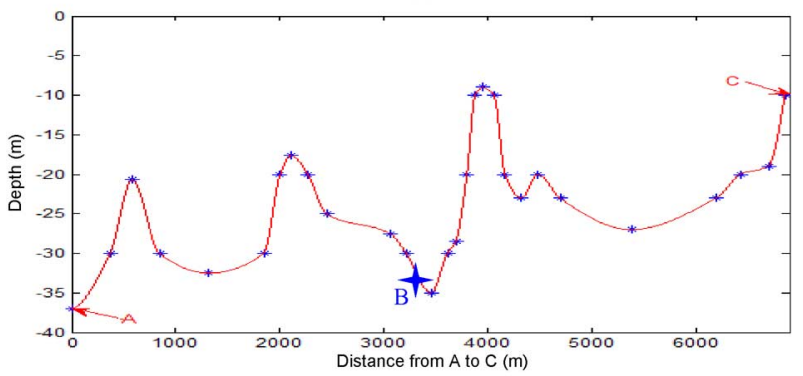

(c)

Fig. 3. (a) Marine current turbine expected site of installation. (b) Direction and tidal current velocity $4 \mathrm{~h}$ before high water. (c) Depth profile of the site.

marine current turbine. Indeed, this site is located in an alternating current area [Fig. 3(b)], where the depth is about $35 \mathrm{~m}$ [Fig. 3(c)], which will allow the installation of a marine current turbine with blades of about 20-m diameter (the maximal swell amplitude is about $10 \mathrm{~m}$ in this area).

It should be noted that tidal current data are provided by the French Navy Hydrographic and Oceanographic Service 


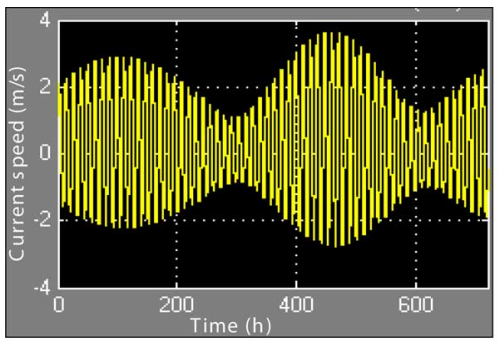

(a)

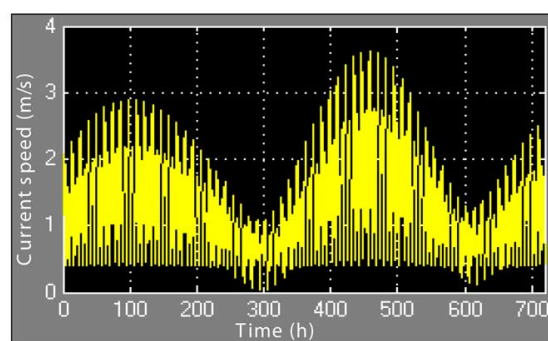

(b)

Fig. 4. Resource Simulink bloc model output.

(SHOM, Brest Armées, France) and is available for various locations in chart form [23].

2) Resource Modeling Under Matlab-Simulink: Considering all the previous data, the resource has been modeled at site B which has the following global positioning system (GPS, WGS84) coordinates:

$$
\left\{\begin{array}{l}
\varphi_{B}=48^{\circ} 02^{\prime} 42^{\prime \prime} \mathrm{N} \\
G_{B}=004^{\circ} 45^{\prime} 45^{\prime \prime} \mathrm{W}
\end{array}\right.
$$

The SHOM available charts give, for a specific site, the current velocities for spring and neap tides. These values are given at hourly intervals starting at $6 \mathrm{~h}$ before high waters and ending $6 \mathrm{~h}$ after. Therefore, knowing tide coefficients, it is easy to derive a simple and practical model for tidal current velocities $V_{\text {tide }}$

$$
V_{\text {tide }}=V_{n t}+\frac{(C-45)\left(V_{s t}-V_{n t}\right)}{95-45}
$$

where $C$ is the tide coefficient ( 95 and 45 are, respectively, the spring and neap tide medium coefficient) and $V_{s t}$ and $V_{n t}$ are, respectively, the spring and neap tide current velocities.

This first-order model is then used to calculate the tidal velocity each hour. The implemented model will allow the user to compute tidal velocities in a predefined time range. Fig. 2 shows the model output for a month (March 2007) and for a year (2007). It should be noticed that the current velocity peak values will be taken into account in the choice of the marine turbine.

Fig. 4(a) shows, then, the resource Simulink bloc model output according to (3) for a month. The tidal current is then rectified so as not to get negative power [Fig. 4(b)].

3) Modeling Summary: The first-order model which has been adopted for the resource has several advantages including its modularity not to mention its simplicity. Indeed, the marine turbine site can be changed, the useful current velocity can be adapted, and the time range taken into account can also be adapted from one month to one year.

\section{ROTOR MODELING}

The harnessing of the energy in a tidal flow requires the conversion of kinetic energy in a moving fluid, in this case water, into the motion of a mechanical system, which can then drive a generator. It is not too surprising, therefore, that many developers suggest using technology that mirrors that which has been successfully utilized to harness the wind, which is also a moving fluid [24]. Moreover, much of the technology is based upon the

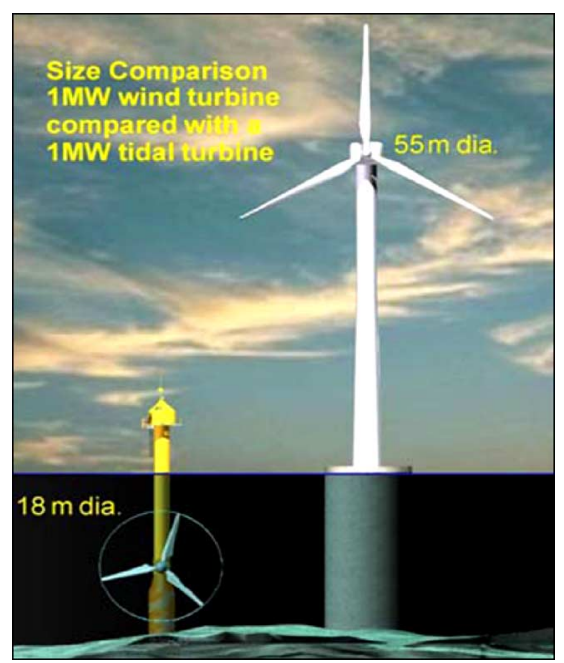

Fig. 5. Tidal turbine against an offshore wind turbine [Marine Current Turbine (@ MCT, Bristol, U.K., www.marineturbines.com)].

use of horizontal axis turbines, such as that shown in Fig. 5 [25]. Therefore, much can be transferred from the design and operation of wind turbines [26]. There is, however, a number of fundamental differences in the design and operation of marine turbines. Particular differences entail changes in force loadings, immersion depth, different stall characteristics, and the possible occurrence of cavitation. Much information is, however, available on the cavitation and stall characteristics of marine propellers [27], which can provide useful information for marine turbines [28], [29].

\section{A. Marine Turbine Hydrodynamics}

The hydrodynamic design parameters basically entail the choice of diameter, pitch, and speed for a particular application. Further design criteria include the pitch or twist distribution across the blade span, the stall characteristics, the blade section choice, and the need to preclude the cavitation occurrence. The hydrodynamic design is further complicated by changes in the nonuniform speed and the current direction, the shear profile in the tidal flow, and the influences of water depth and the free surface [29].

Bearing in mind that the simulation model has two purposes, performance and dynamic load assessment in different operating conditions and further control system development for turbine operation based on pitch and speed control, it is, therefore, necessary to find a compromise between the simulation model 


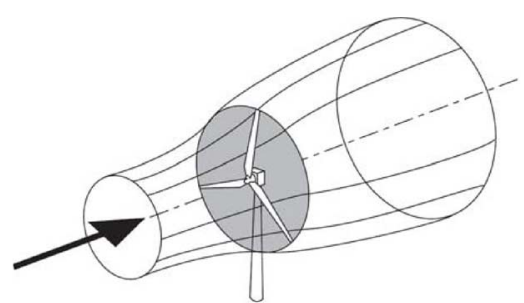

(a)
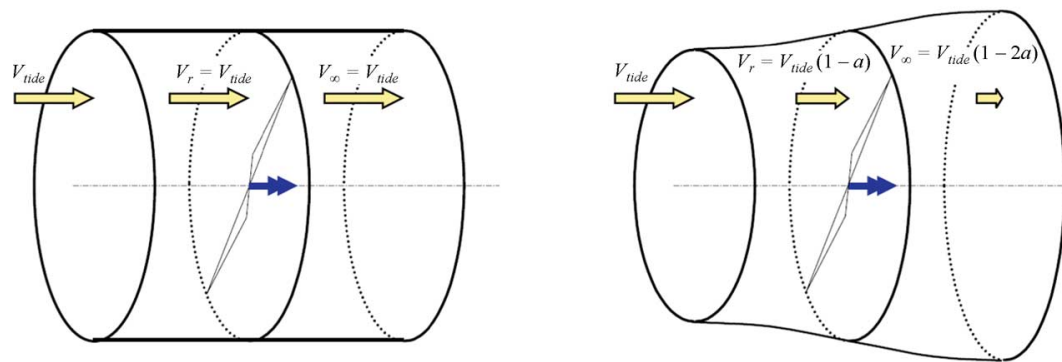

(b)

Fig. 6. Actuator-disk model. (a) Energy extracting stream tube of a wind/marine turbine. (b) marine turbine with (right) and without (left) loading.

accuracy and the control loop computational speed. Moreover, modeling the turbine rotor is done in the following two steps: 1) performance curve assessments that are 2) integrated into a dynamic simulation environment.

Turbine rotor aerodynamics refers to the interaction of the wind turbine rotor with the incoming wind. The treatment of rotor aerodynamics in all current design codes is based on Glauert well-known and well-established BEM theory [30]. This theory is an extension of the Rankine-Froude actuator-disk model which aims to overcome the unsatisfactory accuracy performance predictions based on this model.

The BEM method has, therefore, been used for the marine turbine rotor modeling. Indeed, it is widely used in the industry as a computational tool to predict aerodynamic loads and the power of turbine rotors. It is relatively simple and computationally fast meeting the aforementioned requirements of the simulation model [31].

\section{B. Rankine-Froude Actuator-Disk Model [26], [32]}

In this model, the rotor is replaced by an actuator disk, which is a circular surface of zero thickness that can support a pressure difference, and thus decelerate the tidal current through the disk. Physically, the disk could be approximated by a rotor with an infinite number of very thin, dragless blades rotating with a tip speed much higher than the tidal current velocity. The actuatordisk model is thus an approximation of a real marine turbine rotor (which has only a small number of blades). As a result, the flow of the actuator disk will be very different from that of a real rotor, which is unsteady, with a wake of discrete vorticity corresponding to the discrete loading.

The principal use of the actuator-disk model is to obtain a first estimate of the wake-induced flow, and hence, the total induced power loss. Note that the actual induced power loss will be larger than the actuator-disk result because of the nonuniform and unsteady induced velocity. The assumptions on which the Rankine-Froude actuator-disk theory is based are well detailed in [32]. Among these assumptions, one requires that the disk slows the tidal current equally at each radius, which is equivalent to assuming uniform thrust loading at the disk. Uniform thrust loading is, in turn, equivalent to considering an infinite number of rotor blades.

Fig. 6 illustrates the 1-D flow through the actuator-disk plane for a nonloaded and loaded machine. For instance, for a turbine with zero loading, the current velocity in the rotor plane $\left(V_{r}\right)$ is equal to the undisturbed tidal current velocity $\left(V_{\text {tide }}\right)$, while an operating and hence loaded turbine slows down the current velocity to a lower value. If the velocity decrease induced by the rotor is $v$, then the velocity at the disk is $V_{\text {tide }}-V=V_{r}$, while far downstream in Section I the current has been slowed further to velocity $V_{\infty}$. The difference between the axial component of the current velocity and the axial flow velocity in the rotor plane is usually called the induced velocity.

Thus, the velocity at the disk is the average of the upstream and downstream velocities. The axial induction factor $a$, defined as the fractional decrease in current velocity between the free stream and the rotor plane, is given by

$$
a=\frac{V}{V_{\text {tide }}} \text {. }
$$

It follows that

$$
\left\{\begin{array}{l}
V_{r}=V_{\text {tide }}(1-a) \\
V_{\infty}=V_{\text {tide }}(1-2 a)
\end{array}\right.
$$

For $a=0$, the current is not decelerated and no power is extracted, whereas for $a=0.5$, the far wake velocity vanishes, and, without presence of flow behind the turbine, no power is generated.

The power extracted from the tidal current by the rotor is given by

$$
P=\frac{1}{2} \rho A V_{r}\left(V-V_{\infty}\right)\left(V+V_{\infty}\right) .
$$

Substituting $V_{r}$ and $V_{\infty}$ from (5), we find that

$$
P=\frac{1}{2} \rho A V_{\text {tide }}^{3} 4 a(1-a)^{2} \text {. }
$$




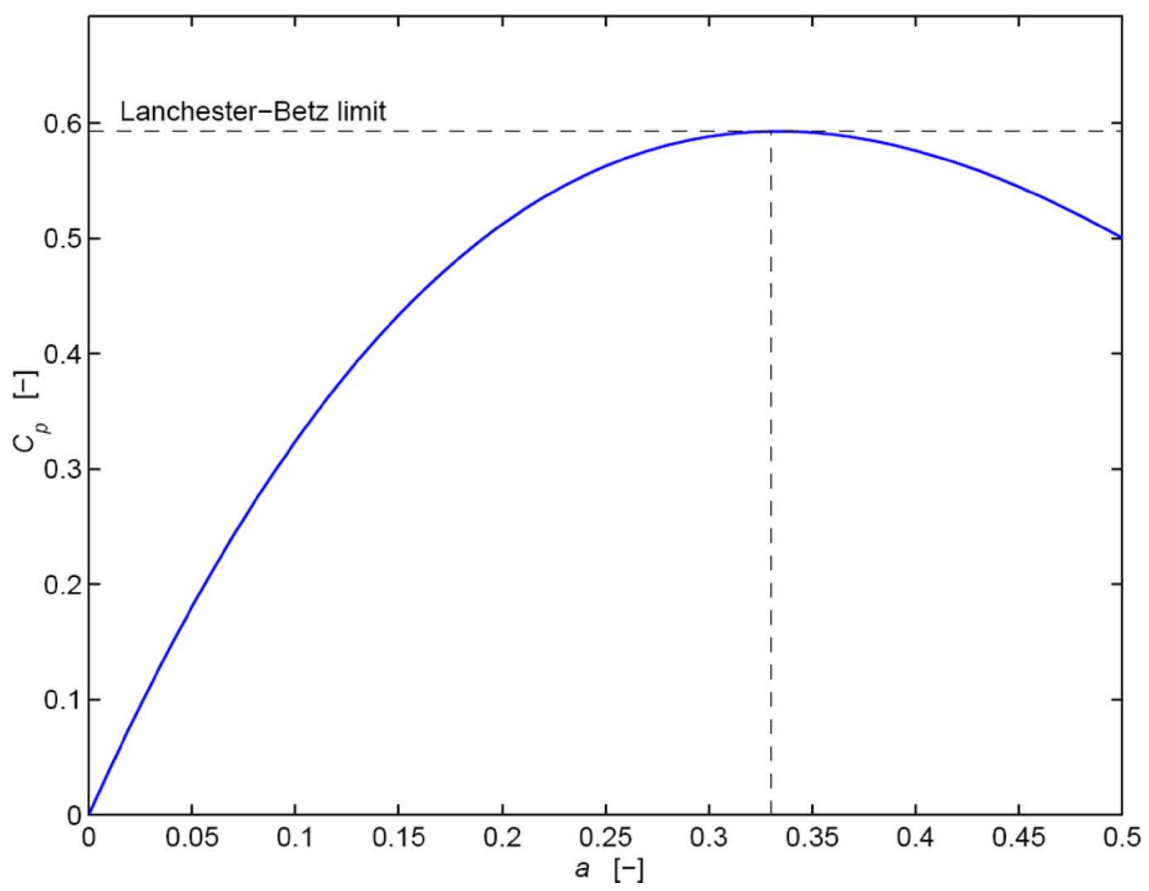

Fig. 7. Power coefficient $C_{p}$ as a function of the axial induction factor $a$ [32].

A power coefficient $C_{p}$ is then defined as

$$
C_{p}=\frac{P}{\frac{1}{2} \rho A V_{\text {tide }}^{3}}=4 a(1-a)^{2}
$$

where the denominator represents the kinetic energy of the freestream current contained in a stream tube with an area equal to the disk area.

The maximum value of the power coefficient $C_{p}$ occurs when $a=1 / 3$. Hence, $C_{p, \max }=16 / 27 \approx 0.59259$, $V_{r}=(2 / 3) V_{\text {tide }}$, and $V_{\infty}=(1 / 3) V$. Thus, the maximum amount of energy extraction equals the $16 / 27$ th part of the kinetic energy in the current. This limit is often referred to as the Betz limit, or more accurately, the Lanchester-Betz limit. The power coefficient $C_{p}$ versus the induction factor $a$ is shown in Fig. 7.

Additional data that can be derived from this model include the thrust loading on the rotor

$$
D_{r}=\frac{1}{2} \rho A\left(V_{\text {tide }}^{2}-V_{\infty}^{2}\right)=\frac{1}{2} \rho A V_{\text {tide }}^{2}[4 a(1-a)] .
$$

Moreover, if this thrust loading is considered as a drag force on the rotor, we can define a drag coefficient as follows:

$$
C_{d r}=\frac{D_{r}}{\frac{1}{2} \rho A V_{\text {tide }}^{2}}=4 a(1-a) .
$$

Since a flat plate has a drag coefficient of about 1.28 , we can note that, for $a=1 / 3$, we obtain an equivalent drag coefficient of $8 / 9$ for a rotor operating at the maximum $C_{p}$ condition. Thus, the rotor thrust is about $30 \%$ less than that of a flat plate equal in diameter to the rotor. Therefore, it is easy to see that the thrust loads generated by continuing to operate in high currents can be very large, requiring a very strong rotor and pile.

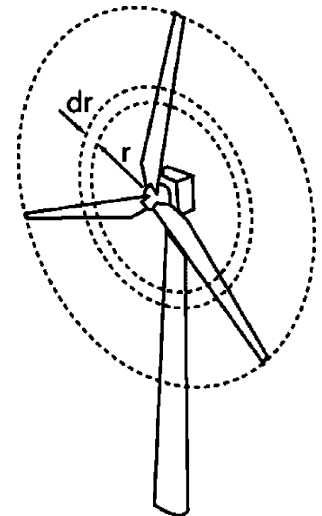

Fig. 8. Annular plane used in BEM theory.

\section{BEM Model}

BEM theory is one of the oldest and most commonly used methods for calculating induced velocities on wind turbine blades. This theory is an extension of the previously studied actuator-disk theory. BEM theory assumes that blades can be divided into small elements that act independently of surrounding elements and operate hydrorodynamically as 2-D airfoils whose hydrodynamic forces can be calculated based on the local flow conditions. These elemental forces are summed along the span of the blade to calculate the total forces and moments exerted on the turbine. The other half of BEM, the momentum theory, assumes that the loss of pressure or momentum in the rotor plane is caused by the work done by the fluid flow passing through the rotor plane on the blade elements. Using the momentum theory, one can calculate the induced velocities from the momentum lost in the flow in the axial and tangential directions. These induced velocities affect the inflow in the rotor plane and, therefore, also affect the forces 


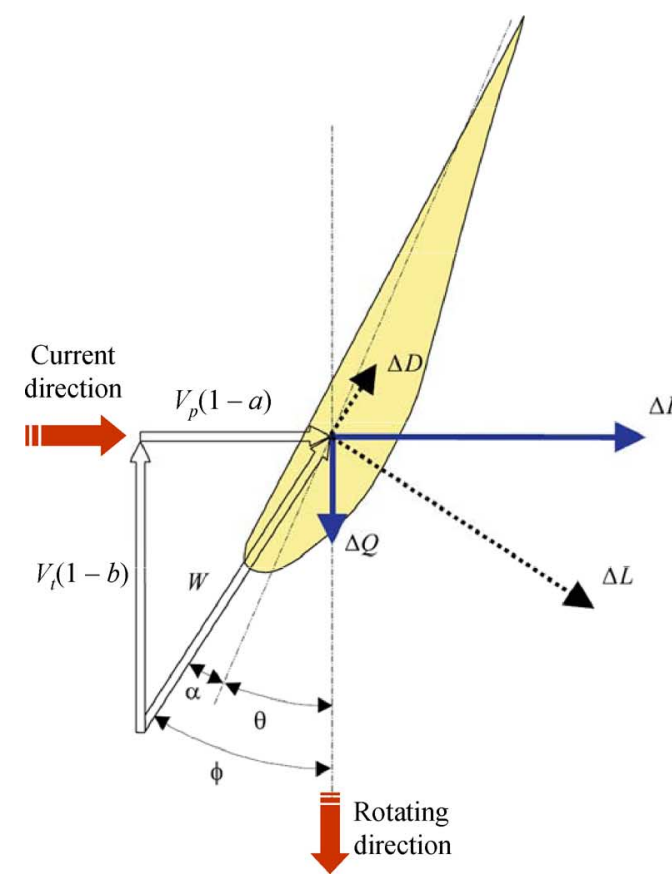

$\Delta L=$ Blade element lift force.

$\Delta D=$ Blade element drag force.

$\Delta F=$ Hydrodynamic forces axial components.

$\Delta Q=$ Hydrodynamic forces tangential components.

$\Omega=$ Turbine rotation speed.

$V_{p}=$ Local, undisturbed, perpendicular current velocity.

$V_{t}=$ Local, undisturbed, tangential current velocity.

$W=$ Local, undisturbed, current velocity.

a $=$ Axial induction factor.

b = Tangential induction factor (swirl velocity).

$\alpha=W$ angle of attack.

$\theta=$ Rotor blade pitch angle.

$\phi=W$ direction related to the rotor plane.

Fig. 9. Blade element velocities and hydrodynamic forces in the blade local coordinate frame with the chord line as a reference.

forces calculated by blade element theory. This coupling of two theories ties together BEM theory and sets up an iterative process to determine the hydrodynamic forces and also the induced velocities near the rotor.

In practice, BEM theory is implemented by breaking the blades of a marine turbine into many elements along the span. As these elements rotate in the rotor plane, they trace out annular regions, shown in Fig. 8, across which the momentum balance takes place. These annular regions are also the areas where the induced velocities from the wake change the local flow velocity at the rotor plane. BEM can also be used to analyze stream tubes through the rotor disk, which can be smaller than the annular regions and provide more computational fidelity [31], [33].

The contribution of each blade element to the lift and drag force can be derived as follows. Consider an annular cross section of a rotor blade as depicted in Fig. 9, and examine an element of length $\Delta r$ of one blade. The net effect on current flowing through this annular section of the rotor disk results from the forces and moments on all the blades. The instantaneous relative undisturbed wind velocity experienced by a blade element is

$$
\begin{aligned}
W & =\sqrt{\left[V_{p}(1-a)\right]^{2}+\left[V_{t}(1+b)\right]^{2}} \\
\text { under an angle } \phi & =\arctan \left(\frac{V_{p}(1-a)}{V_{t}(1+b)}\right) .
\end{aligned}
$$

It must be noted that the tangential induction factor $b$ in (11) and (12) is as a rule an order smaller than the axial induction factor $a$ [26].

Due to the resultant velocity $W$, the blade cross section exerts a quasi-steady hydrodynamic lift force

$$
\Delta L=\frac{1}{2} \rho c W^{2} C_{L} \Delta r
$$
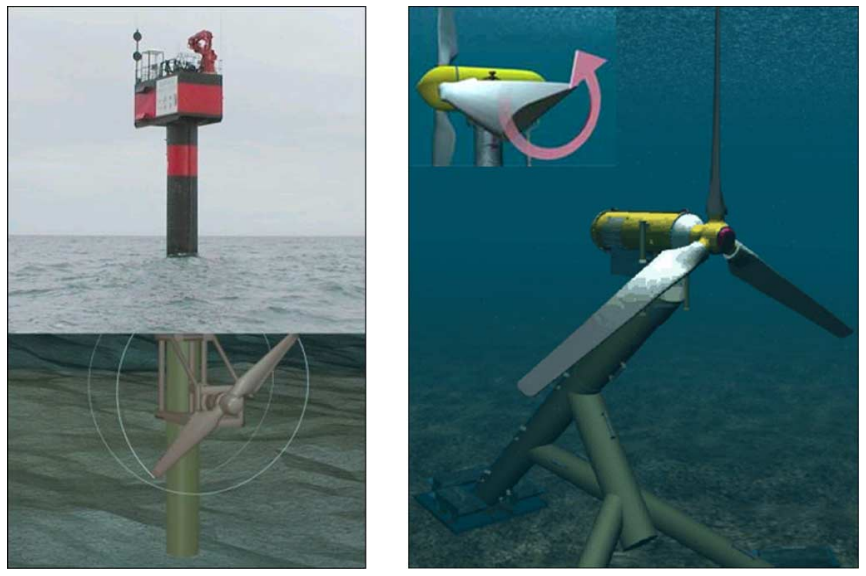

Fig. 10. Two- (Seaflow) and three-blade (E-tide) options [@ MCT and Strøm AS, Norway].

and a quasi-steady hydrodynamic drag force

$$
\Delta D=\frac{1}{2} \rho c W^{2} C_{D} \Delta r
$$

where $c$ is the local blade chord, $C_{L}$ is the blade element 2-D lift coefficient, $C_{D}$ is the blade element 2-D drag coefficient, and $\Delta r$ is the blade section length. The dimensionless hydrodynamic coefficients $C_{L}$ and $C_{D}$-among other things-are functions of the attack angle $\alpha$ and the Reynolds number.

The axial-induced velocity can be determined by expressing the axial thrust $\Delta F$ on a blade element as the rate of change of momentum in the annular ring swept out by this element. On the other hand, the tangential-induced velocity can be determined by expressing the torque $\Delta Q$ on a blade element as the rate of change of angular momentum

$$
\left\{\begin{array}{l}
\Delta F=4 \rho \pi r V_{p}^{2} a(1-a) \Delta r \\
\Delta Q=4 \rho \pi r^{2} V_{t} V_{p} b(1-a) \Delta r
\end{array} .\right.
$$




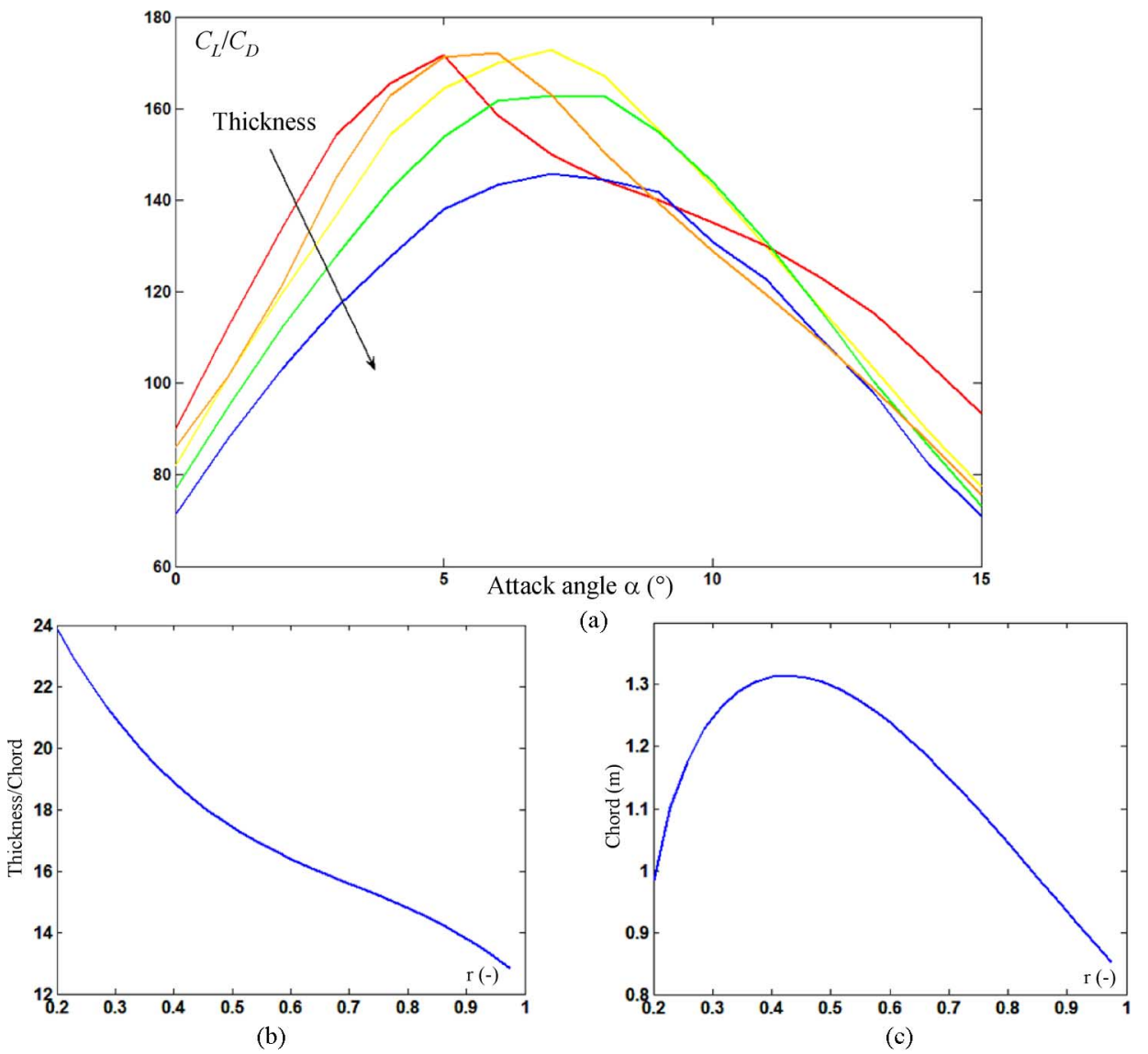

Fig. 11. NACA 44 blades derived characteristics. (a) Lift over drag coefficient ratio according to the attack angle. (b) Thickness law. (c) Chord law.

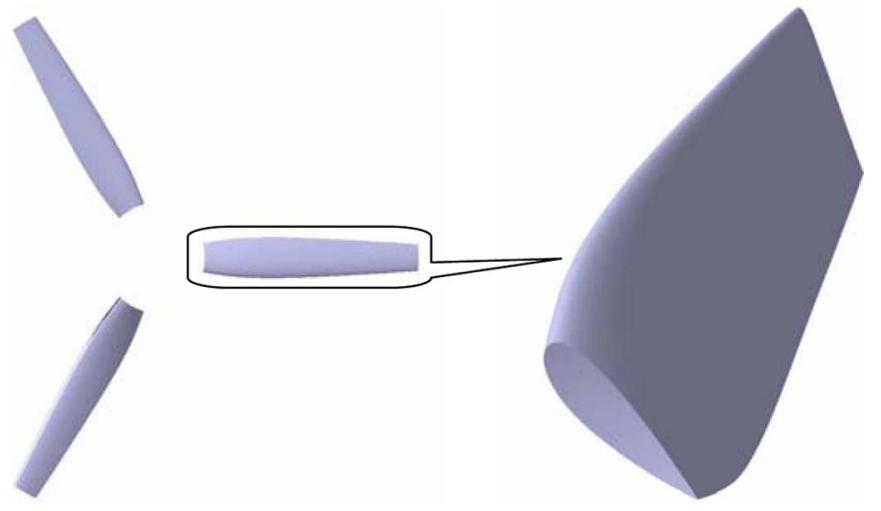

Fig. 12. Blades mesh using singularités code.

The previous equations will lead to the calculation of both axial and tangential coefficients

with

$$
\left\{\begin{array}{l}
a=\frac{\sigma_{r} C_{N}}{4 \sin ^{2} \phi+\sigma_{r} C_{N}} \\
b=\frac{\sigma_{r} C_{T}}{4 \sin \phi \cos \phi-\sigma_{r} C_{T}}
\end{array}\right.
$$

$$
\left\{\begin{array}{l}
C_{N}=C_{L} \cos \phi+C_{D} \sin \phi \\
C_{T}=C_{L} \sin \phi-C_{D} \cos \phi
\end{array} \text { and } \sigma_{r}=\frac{N_{b} c}{2 \pi r}\right.
$$

where $N_{b}$ is the blade number and $\sigma_{r}$ is the chord solidity.

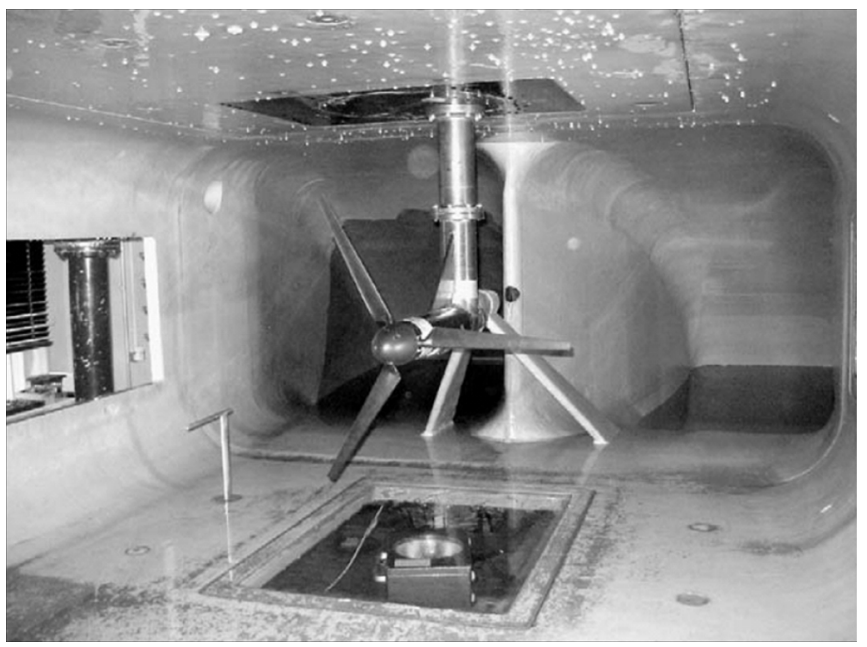

Fig. 13. Marine turbine tested in [39]. (Illustration reproduced with the kind permission of the authors.)

Because of its simplicity, the BEM theory does have its limitations. To overcome the restricting assumptions of the previously briefly described BEM method, in state-of-the-art aeroelastic codes for wind turbines, a number of semiempirical corrections is applied [31]. An overview of BEM-based rotor aerodynamics in comparison to other computational methods can be found in [34]. 


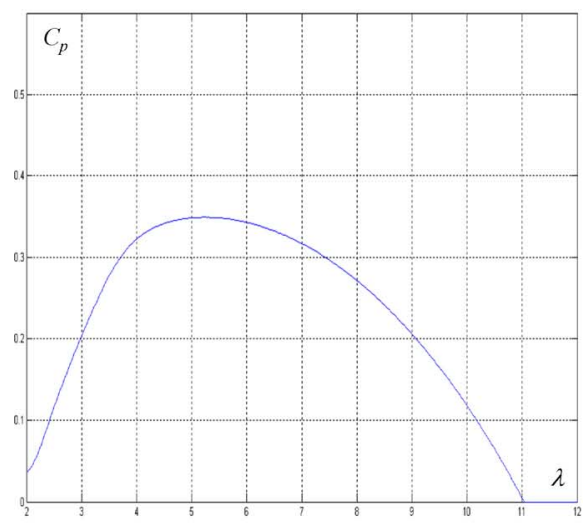

(a)

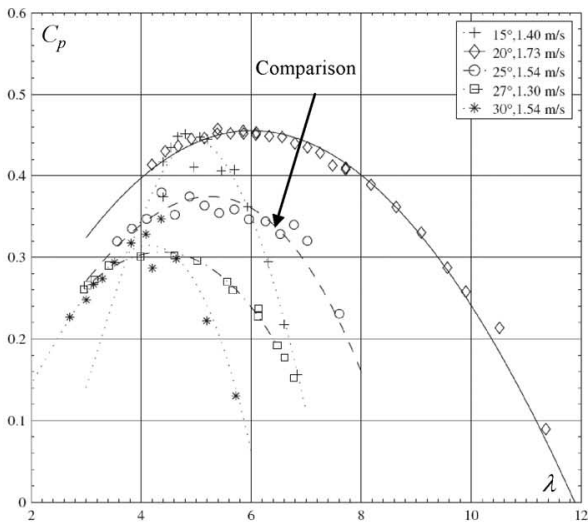

(b)

Fig. 14. (a) Model and (b) experimental $C_{p}$ curves [39].

Two corrections have been adopted for the proposed simulation model. The first one takes into account the so-called blade tip and root effects. In this case, (16) becomes

$$
\left\{\begin{array}{l}
a=\frac{\sigma_{r} C_{N}}{4 F_{L} \sin ^{2} \phi+\sigma_{r} C_{N}} \\
b=\frac{\sigma_{r} C_{T}}{4 F_{L} \sin \phi \cos \phi-\sigma_{r} C_{T}}
\end{array}\right.
$$

where $F_{L}$ is Prandtl combined blade tip and blade root loss factor.

The second correction concerns the turbulent wake state. In this case, we have adopted the Glauert empirical relation [35]

$$
a=0.143+\sqrt{0.6427 C_{d r}-0.55106}
$$

for $C_{d r}>0.96$.

\section{Rotor Design Options}

The choice of three blades was made after considering both two- and three-blade options (Fig. 10). Rotors with three blades have the advantage of being slightly more efficient and they are also more balanced, inducing less fatigue load on the gearbox and the structure. The orientation of the rotor is fixed, but the blades can be pitched through $180^{\circ}$, so that it can be used for currents in both directions, either on the ebb or the flood tide. The turbine rotor can be changed from operating on a flood tide to an ebb tide simply by reversing the blades, pitching them through $180^{\circ}$ (Fig. 10). The ability to pitch also meant that the blade angle could be optimized in any given current, the blades could be feathered to brake the rotor gently, and the maximum power generated could be limited by angling the blades away from the optimum position. It was, therefore, decided to implement full-length blade pitch control.

Some suitable section data is applicable from wind turbines [36] and recent cavitation tunnel tests [37]. For the numerical predictions of section performance used for the simulation model, the 2-D panel code XFoil [38] was used. Indeed, XFoil is a linear vorticity stream function panel method with viscous boundary layer and wake model.

Section shape is governed by hydrodynamic performance and structural design. As with a wind turbine, to operate over a wide range of conditions, a wide range of lift coefficient $\left(C_{L}\right)$ is desirable, with delayed separation and stall. In the case of a marine current turbine, it is also desirable that the section shape is such that cavitation inception is delayed. From an efficiency point of view, a low drag coefficient $\left(C_{D}\right)$ is also required. Structural requirements, however, tend to lead to relatively thick sections, particularly near the root, with ensuing higher drag coefficient [29]. We have, therefore, adopted the National Advisory Committee for Aeronautics (NACA 44) profile shape [22]. Fig. 11 shows the main derived characteristics of the previously chosen blades. Moreover, the rotor mesh shown by Fig. 12 has been done using a code called singularités developed by the French Naval Academy Research Institute (IRENav, Brest Armées, France).

\section{E. Validation of the Proposed Model}

For validation purposes, we have compared the simulation model output to the experimental data from the available literature [28], [39]. These data are experimental results for the power coefficient $C_{p}$ to a base of tip speed ratio $\left(\lambda=R \Omega / V_{\text {tide }}\right.$, where $R$ is the turbine radius and $\Omega$ is the rotor rotational speed).

The first simulated marine turbine corresponds to the one tested in [39] (Fig. 13). The obtained power coefficient is shown by Fig. 14: For a 0.8-m model of a marine current turbine, a current velocity $V_{\text {tide }}=1.5 \mathrm{~m} / \mathrm{s}$ and a pitch angle $\theta=25^{\circ}$; a $C_{p}$ of about 0.349 was found in comparison to 0.375 in the tank test. This is an encouraging result as it is not possible to reproduce the exact experimental conditions by simulation. Quite the same error was found for other current velocities and pitch angles.

\section{F. Simulation Results in the Raz de Sein}

For the Raz de Sein site, the maximum current velocity is about $3.63 \mathrm{~m} / \mathrm{s}$ for 2007 . We have, therefore, adopted a ratio of $75 \%$ for economically viable operation of the marine turbine [21], [40]. In fact, it has been shown, in [21] and according to wind power experience, that an installed capacity of a site should be rated for a velocity equal to 0.75 (or lower) times the peak velocity at the site to be more economic. In our case, this leads to a turbine rotor design with $2.72 \mathrm{~m} / \mathrm{s}$ for optimal operation. Moreover, simulations are based on a marine turbine with blades of about 17.4-m diameter and of about $1 \mathrm{MW}$ (net electric power) for future marine current converter array deployment. In this context, the obtained power coefficient $C_{p}$ curves are shown by Fig. 15 . 

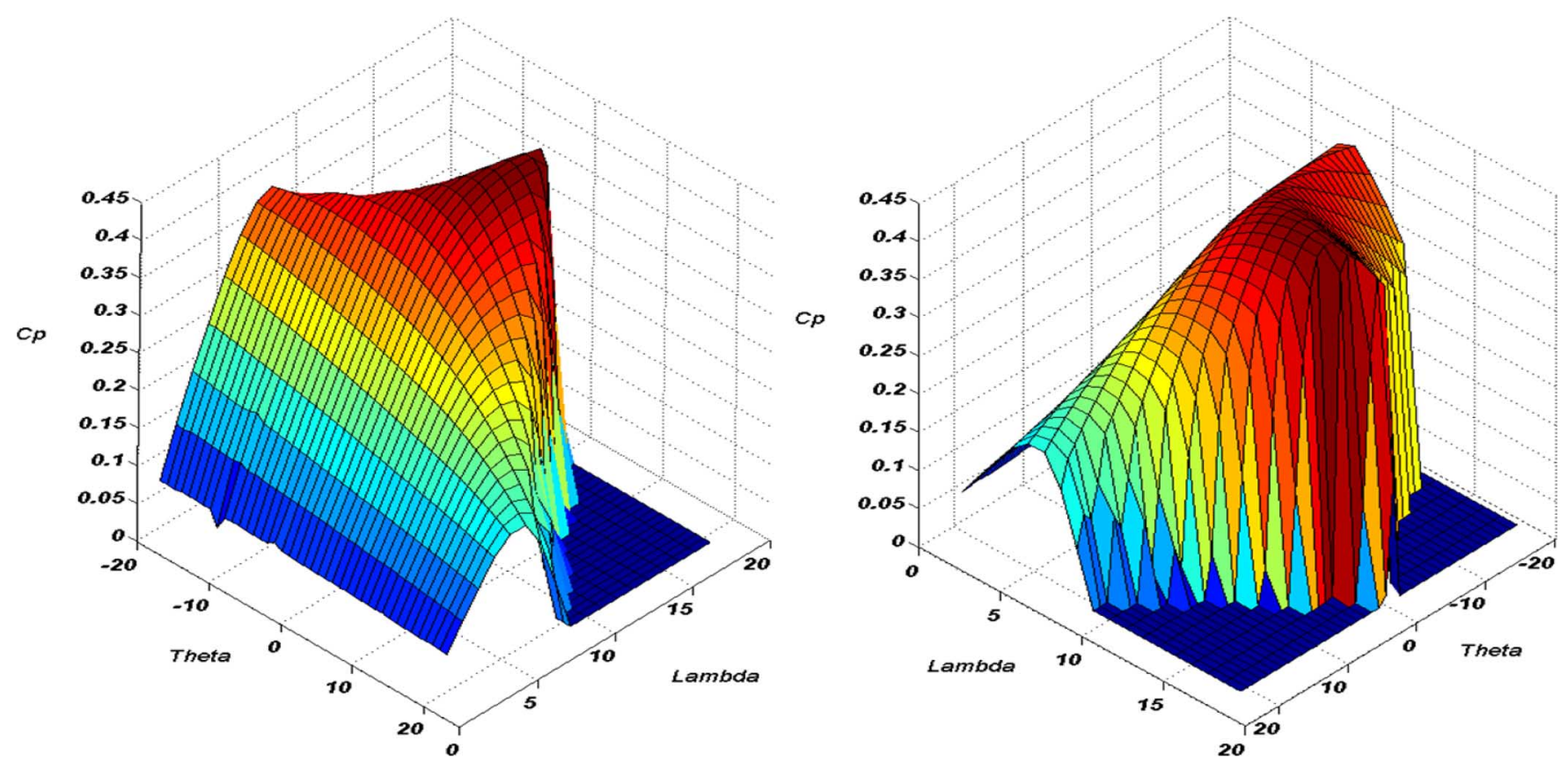

Fig. 15. $C_{p}(\lambda, \theta)$ curves.
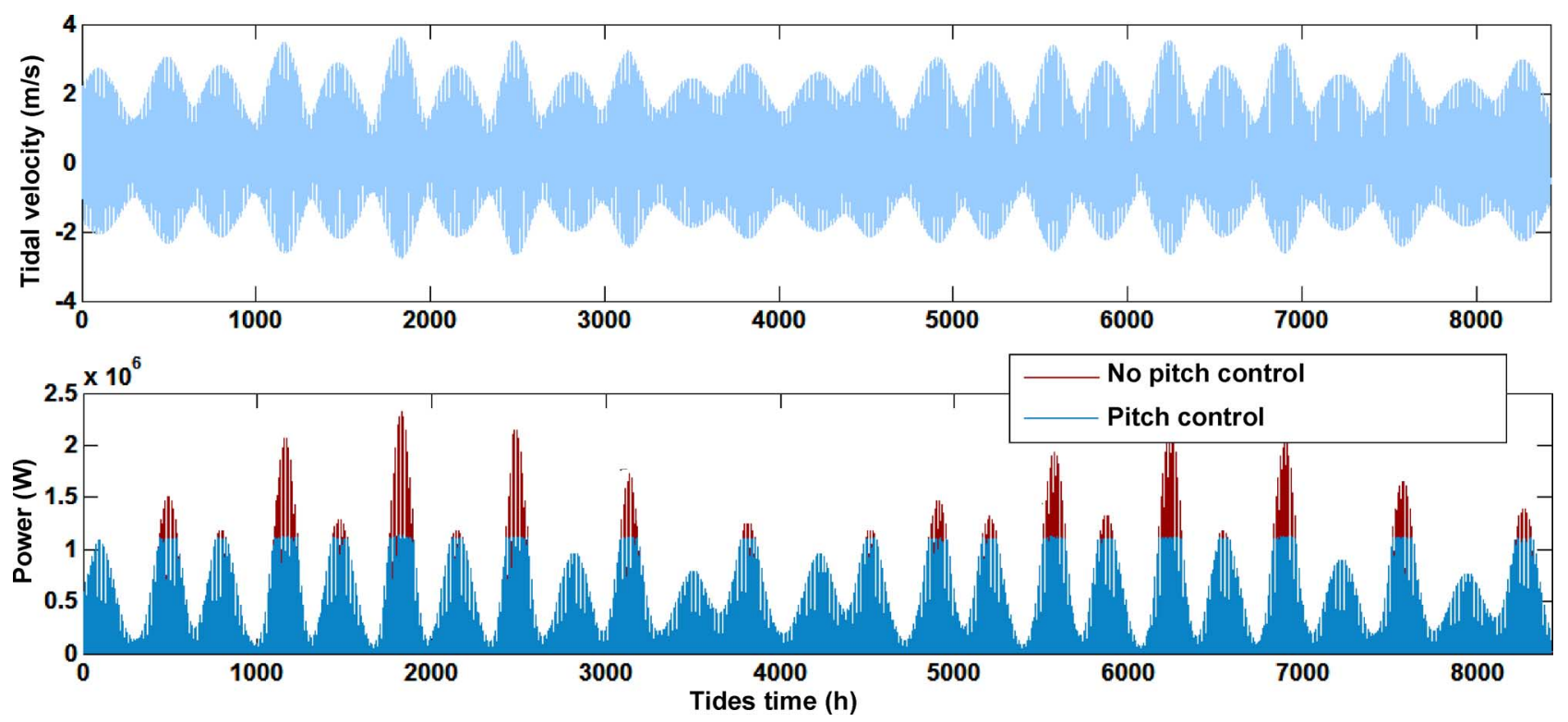

Fig. 16. Estimated extracted power for year 2007.

Now, the whole simulation tool is used including the resource and the rotor models. The tool input data are those corresponding to optimal operation $\left(V_{\text {tide }}=2.72 \mathrm{~m} / \mathrm{s}\right)$. The expected output power of the turbine rotor is about $1.108 \mathrm{MW}$ taking into account gearbox and generator efficiencies as $95 \%$ [40]. In this simulation context, the obtained results are shown by Figs. 16 and 17. They are very promising. Indeed, the following two relevant points are noticed: the maximum output power is about $1.13 \mathrm{MW}$ leading to a relative error of $2 \%$ and it is well known that the adopted marine current turbine cannot produce power from water current flow as low as $1 \mathrm{~m} / \mathrm{s}$. This fact is taken into account by the simulation model as shown by Fig. 17.

\section{CONCLUSION}

This paper has proposed a Matlab-Simulink-based simulation tool for marine current turbines through the modeling of the resource and the rotor. In this case, the BEM approach has been used for the turbine modeling. Two corrections have been added to the BEM. The first one takes into account the so-called blade tip and root effects and the second one concerns the turbulent wake state, where the Glauert empirical relation is adopted. A part of the proposed simulation tool has been validated based on the rare experimental results available in literature. It has then been applied to assess the extractable power from the Raz de Sein. In this case, tidal current data from the Raz de Sein are 


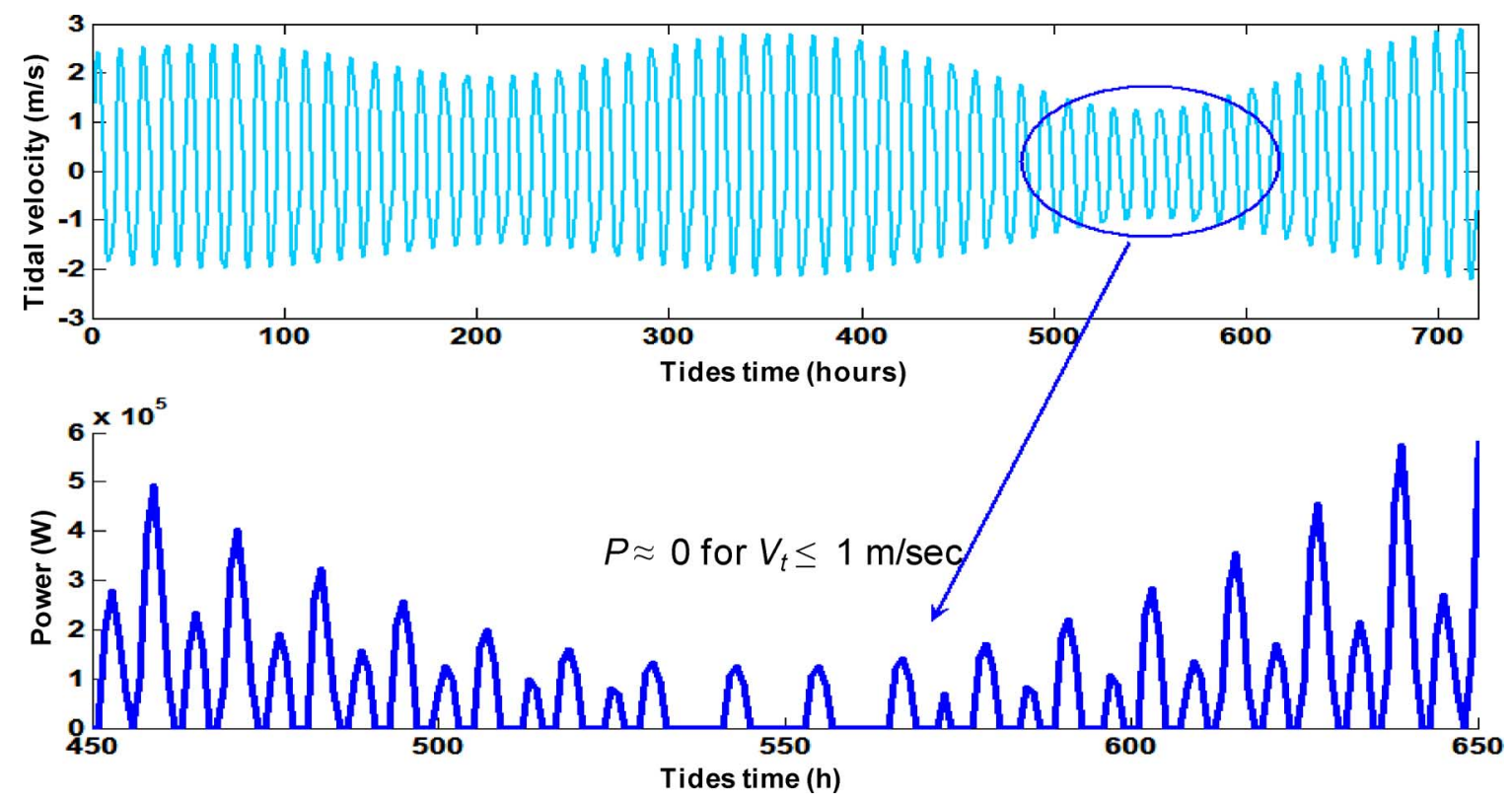

Fig. 17. Estimated extracted power for July 2007.

used to run the simulation models over various flow regimes and yield the power capture with time. The obtained results are consistent and very promising.

\section{REFERENCES}

[1] A. T. Jones and A. Westwood, "Recent progress in offshore renewable energy technology development," in Proc. IEEE Power Eng. Soc. General Meeting Panel Session, San Francisco, CA, Jun. 2005, vol. 2, pp. 2017-2022.

[2] R. Ramakumar, N. G. Butler, A. P. Rodriguez, and S. S. Venkata, "Economic aspects of advanced energy technologies," Proc. IEEE, vol. 3 , no. 3, pp. 318-332, Mar. 1993.

[3] G. T. Heydt, "An assessment of ocean thermal energy conversion as an advanced electric generation methodology," Proc. IEEE, vol. 3, no. 3, pp. 409-418, Mar. 1993.

[4] C. M. Johnstone, K. Nielsen, T. Lewis, A. Sarmento, and G. Lemonis, "EC FPVI co-ordinated action on ocean energy: A European platform for sharing technical information and research outcomes in wave and tidal energy systems," Renew. Energy, vol. 31, pp. 191-196, 2006.

[5] L. B. Bernshtein, "Tidal power development-A realistic, justifiable and topical problem of today," IEEE Trans. Energy Convers., vol. 10, no. 9, pp. 591-599, Sep. 1995.

[6] T. J. Hammons, "Tidal power," Proc. IEEE, vol. 3, no. 3, pp. 419-433, Mar. 1993.

[7] P. Meisen and T. Hammons, "Harnessing the untapped energy potential of the oceans: Tidal, wave, currents and OTEC," in Proc. IEEE Power Eng. Soc. General Meeting Panel Session, San Francisco, CA, Jun. 2005, pp. 1-49.

[8] "Non nuclear energy_JOULE II, wave energy project results: The exploitation of tidal marine currents," Non-Nuclear Energy R\&D Component, Technomare SpA (Italy)/IT Power Ltd. (U.K.), EU JOULE Contract JOU2-CT94-0355, 1996.

[9] P. W. Ullman, "Offshore tidal power generation-A new approach to power conversion of the oceans' tides," Mar. Technol. Soc. J., vol. 36, no. 4, pp. 16-24, 2002.

[10] I. G. Bryden and G. T. Melville, "Choosing and evaluating sites for tidal current development," Proc. IMechE, A: J. Power Energy, vol. 218, no. 8 , pp. $567-578,2004$.

[11] B. V. Davis, "Low head tidal power: A major source of energy from the world's oceans," in Proc. IEEE Intersoc. Energy Convers. Eng. Conf., Honolulu, HI, Jul./Aug. 1997, vol. 3, pp. 1982-1989.

[12] I. G. Bryden, C. Bullen, M. Baine, and O. Paish, "An assessment of tidal streams as energy sources in Orkney and Shetland," Underwater Technol., vol. 21, no. 2, pp. 21-29, 1995.
[13] I. G. Bryden, "Tidal stream power for Orkney and Shetland?," Underwater Technol., vol. 9, no. 4, pp. 7-11, 1993.

[14] A. S. Bahaj and L. E. Myers, "Simulated electrical power potential harnessed by marine current turbine arrays in the Alderney Race," Renew. Energy, vol. 30, pp. 1713-1731, 2005.

[15] T. G. Pugh, Tides, Surges and Mean Sea-Level. London, U.K.: Wiley, 1987.

[16] L. S. Blunden and A. S. Bahaj, "Initial evaluation of tidal stream energy resources at Portland Bill, UK," Renew. Energy, vol. 31, pp. 121-132, 2006.

[17] I. G. Bryden, T. Grinsted, and G. T. Melville, "Assessing the potential of a simple tidal channel to deliver useful energy," Appl. Ocean Res., vol. 26, pp. 198-204, 2004.

[18] S. J. Couch, I. G. Bryden, and, "Tidal current energy extraction: Hydrodynamic resource characteristics," Proc. IMechE, M: J. Eng. Maritime, vol. 220, no. 4, pp. 185-194, 2006.

[19] A. S. Bahaj and L. E. Myers, "Fundamentals applicable to the utilization of marine current turbines for energy production," Renew. Energy, vol. 28, pp. 2205-2211, 2003.

[20] L. E. Myers and A. S. Bahaj, "Power output performance characteristics of a horizontal axis marine current turbine," Renew. Energy, vol. 31, pp. 197-208, 2006.

[21] "The exploitation of tidal marine currents," Eur. Union Commission, Rep. EUR16683EN, 1996.

[22] L. Myers and A. S. Bahaj, "Simulated electrical power potential harnessed by marine current turbine arrays in the Alderney Race," Renew. Energy, vol. 30, pp. 1713-1731, 2005.

[23] Tidal Current of the Brittany Western Coast: From Goulven to Penmarc'h French Navy Hydrographic and Oceanographic Service (SHOM), Paris, France, 1994.

[24] I. G. Bryden and S. J. Couch, "ME1 - Marine energy extraction: Tidal resource analysis," Renew. Energy, vol. 31, pp. 133-139, 2006.

[25] S. E. Ben Elghali, M. E. H. Benbouzid, and J. F. Charpentier, "Marine tidal current electric power generation technology: State of the art and current status," in Proc. IEEE Int. Electr. Mach. Drives Conf., Antalya, Turkey, May 2007, pp. 1407-1412.

[26] E. Bossanyi, Wind Energy Handbook. New York: Wiley, 2000.

[27] J. S. Carlton, Marine Propellers and Propulsion, 2nd ed. Oxford, U.K.: Butterworth-Heinemann, 2007.

[28] W. M. J. Batten et al. "Experimentally validated numerical method for the hydrodynamic design of horizontal axis tidal turbines," in Ocean Eng., 2006, doi:10.1016/j.oceaneng.2006.04.008.

[29] W. M. J. Batten, A. S. Bahaj, A. F. Molland, and J. R. Chaplin , "Hydrodynamics of marine current turbines," Renew. Energy, vol. 31, pp. 249-256, 2006. 
[30] H. Glauert, The Elements of Airfoil and Airscrew Theory, 2nd ed. Cambridge, U.K.: Cambridge Univ. Press, 1959.

[31] G. Mattarolo et al., "Modelling and simulation techniques applied to marine current turbine," in Proc. Int. Conf. Ocean Energy, Bremerhaven, Germany, 2006, p. 8.

[32] D. Molenaar, "Cost-effective design and operation of variable speed wind turbine," Ph.D. dissertation, Electr. Eng. Dept., Delft Univ., Delft, The Netherlands, 2003.

[33] “AeroDyn Theory Manual,” P. J. Moriarty, Ed. et al., 2005, NREL/TP500-36881.

[34] H. Snel, "Review of the present methods of rotor aerodynamics," Wind Energy, vol. 1, pp. 46-69, 1998.

[35] D. M. Eggleston and F. S. Stoddard, Wind Turbine Engineering Design. New York: Van Nostrand Reinhold, 1987.

[36] C. J. Satchwell and S. R. Tumock, "Structurally-efficient Aerofoils for wind turbines," in Proc. Eur. Wind Energy Conf., Glasgow, Scotland, 1989 , p. 6.

[37] A. F. Molland, A. S. Bahaj, J. R. Chaplin, and W. M. J. Batten, "Measurements and prediction of forces, pressures and cavitation on 2-D sections suitable for marine current turbines," Proc. IMechE, M, J. Eng. Maritime Environ., vol. 12, pp. 127-138, 2004.

[38] M. Drela, "XFoil: An analysis and design system for low Reynolds number airfoils," in Proc. Conf. Low Reynolds Number Airfoil Aerodyn., Jun. 1989, p. 6.

[39] A. S. Bahaj et al., "Power and thrust measurements of marine current turbines under various hydrodynamic flow conditions in a cavitation tunnel and a towing tank," Renew. Energy, vol. 32, pp. 407-426, 2007.

[40] “Commercial prospects for tidal stream power," Dept. Trade Ind. (DTI UK), Rep. ETSU T/06/00209/REP, 2001.

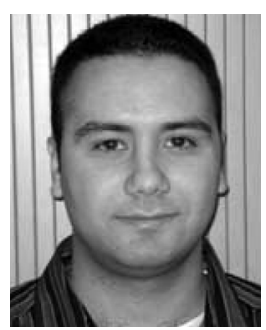

Seif Eddine Ben Elghali (S'04) was born in Téboulba, Tunisia, in 1981. He received the B.Sc. degree in electrical engineering from ENIT, Tunis, Tunisia, in 2005 and the M.Sc. degree in automatic control from the University of Poitiers, Poitiers, France, in 2006. Currently, he is working towards the Ph.D. degree studying on marine tidal turbine modeling and control at the Laboratoire d'Ingénierie Mécanique et Electrique (LIME), University of Western Brittany, Brest Cedex 3, France.

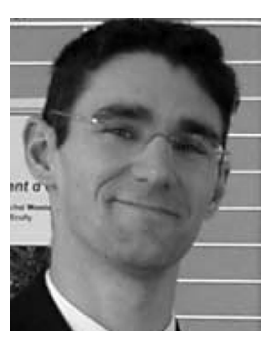

Rémi Balme is currently working towards the B.S. degree at the French Naval Academy, Brest Armées, France.

Currently, he is a Navy Officer at the French Naval Academy.

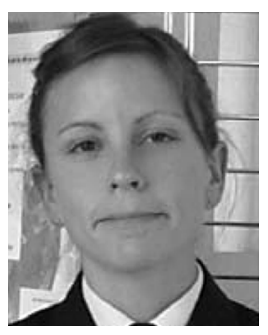

Karine Le Saux is currently working towards the B.S. degree at the French Naval Academy, Brest Armées, France.

Currently, she is a Navy Officer at the French Naval Academy.

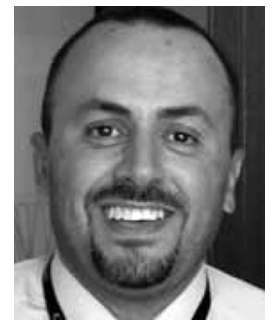

Mohamed El Hachemi Benbouzid (S'92-M'95SM'98) was born in Batna, Algeria, in 1968. He received the B.Sc. degree in electrical engineering from the University of Batna, Batna, Algeria, in 1990, the M.Sc. and Ph.D. degrees in electrical and computer engineering from the National Polytechnic Institute of Grenoble, Grenoble, France, in 1991 and 1994, respectively, and the Habilitation à Diriger des Recherches degree from the University of Picardie "Jules Verne," Amiens, France, in 2000.

$\mathrm{He}$ joined the Professional Institute of Amiens, University of Picardie "Jules Verne," where he was an Associate Professor of electrical and computer engineering. In September 2004, he joined the University Institute of Technology (IUT) of Brest, University of Western Brittany, Brest, France, as a Professor of Electrical Engineering. His main research interests and experience include analysis, design, and control of electric machines, variable-speed drives for traction, propulsion, and renewable energy applications, and fault diagnosis of electric machines.

Prof. Benbouzid is a Senior Member of the IEEE Power Engineering, Industrial Electronics, Industry Applications, Power Electronics, and Vehicular Technology Societies. He is an Associate Editor of the IEEE TRANSACTIONS ON ENERGY CONVERSION, the IEEE TRANSACTIONS ON INDUSTRIAL ELECTRONICS the IEEE TRANSACTIONS ON Vehicular TECHNOLOGY, and the IEEE/ASME TRANSACTIONS ON MECHATRONICS.

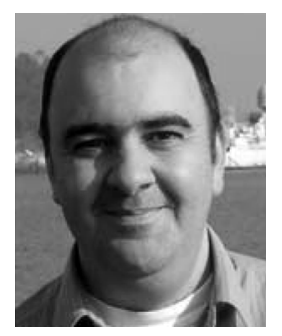

Jean Frédéric Charpentier (M'02) was born in Tananarive, Madagascar, in 1969. He received the M.Sc. and Ph.D. degrees in electrical engineering from the National Polytechnic Institute of Toulouse, Toulouse, France, in 1993 and 1996, respectively.

From 1996 to 1997, he was a Postdoctoral Fellow at Laval University, Québec City, QC, Canada. From 1997 to 2002, he was an Assistant Professor in Electrical Engineering and Electromagnetism at the University Institute of Technology (IUT) of Brest, University of Western Brittany, Brest, France. Since 2002, he has been an Associate Professor in Electrical Engineering a the French Naval Academy, Brest Armées, France. His experience includes magnetic devices, electrical machines and drive analysis, modeling, and design His current research interests include modeling and design aspects of electrical machines and drives for variable speed electrical naval propulsion systems and marine renewable energy.

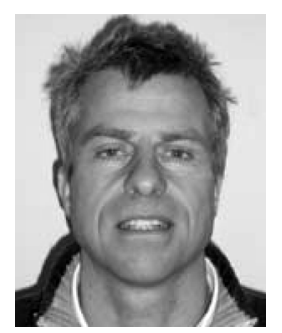

Frédéric Hauville received the Ph.D. degree from the Laboratory of Mechanics, Le Havre University, Le Havre, France, in 1996. During his thesis, he worked on the optimization of calculation methods for unsteady vortical flows to make them usable to study problems over great time intervals (e.g., parallelization)

Since September 1997, he has been an Associate Professor, member of the Hydrodynamic and Propelling Systems group, Research Institute of the French Naval Academy (IRENav), Brest Armées, France. He worked on the modeling of the fluid structure interaction problem applied to sail boat and wind turbines. Since his arrival at the French Naval Academy, he has continued his research activities in numerical hydrodynamic and aerodynamic problems by the development and the coupling of codes His current research interests include problems of fluid structure interaction applied to the deformation of flexible surfaces and the hydrodynamic study of the forced moving foils applied to the unsteady propulsion with numerical and experimental approaches. 